\title{
Application of bio-based material for concrete repair: case study leakage on parallel concrete slab
}

\author{
Prima Yane Putri ${ }^{1,2^{*}}$, Isao $\mathrm{Ujike}^{2}$, and Keiyu Kawaai ${ }^{2}$ \\ ${ }^{1}$ Department of Civil Engineering, Universitas Negeri Padang, Jl. Prof. Dr. Hamka Air Tawar, Padang, 25171, Indonesia \\ ${ }^{2}$ Graduate School of Science and Engineering, Ehime University, Matsuyama, 790-8577, Japan
}

\begin{abstract}
The applicability of bio-based materials for concrete repair has been studied. This technique employs yeast, glucose and calcium acetate mixed in Tris buffer solution. The microbial metabolic process leads to precipitation of calcium carbonate. First, this study investigated the applicability of bio-based repair materials to small-scale concrete specimens. On this research, water permeability test was carried out to evaluate the effectiveness of the selected mixtures for sealing cracks in the concrete specimens. As the result of permeability tests carried out using specimens with crack width of $0.6 \mathrm{~mm}$, water leakage through crack was observed to be negligible after 216 hours by continuous pouring method using bio-based repair materials. Also, this study showed the initial flow rate for the specimens with the same crack width does not influence crack sealing time. Furthermore, the precipitation of the calcium carbonate from the bio-based materials was analyzed by Fourier-Transformed Infra-Red spectroscopy (FT-IR) and then examined by Xray Diffraction (XRD) for mineral identification formed through the microbial metabolic process.
\end{abstract}

\section{Introduction}

Cracking in reinforced concrete structure is likely to occur due to many reasons, for example, restrained shrinkage or mechanical loading or lack of workmanship. Although cracking is usually not an issue of immediate safety, the durability of reinforced concrete is of importance if wide cracks are present in the concrete cover. Most of the codes of practice consider cracks smaller than $0.3 \mathrm{~mm}$ acceptable for aggressive environmental conditions [1], [2]. Some of cracks are not detectable and cannot be accessed [3]. The other factors such as location of the cracking in the damaged structure make repair difficult with conventional repair materials.

The bio-based material technology is a relative recent advance for the improvement of durability and other concrete properties. The application of isolated bacterial cultures and mixed cultures into the fractured concretes was found to seal cracks effectively [4]. This was achieved by the precipitation of calcium carbonate caused by metabolic activity of bacteria. Consequently, the water permeability of the cracked concrete was significantly reduced due to sealing effect of the precipitates. Currently, many researchers study bacteriabased approach, where bacteria is embedded in concrete in order to increase strength and improve durability [5], [6].

In other investigations, bacteria was directly added to the concrete mix instead of spraying and injection approach [7]-[10]. Thus, cracks were plugged by the microbial precipitation due to ureolytic activity of bacteria. This proved to be a better approach compared to spraying and injection approach. However, severe environment within the concrete matrix tends to decrease the lifespan of the bacteria [7]. As a result, the efficiency of crack sealing decreased over time. Thus, it is necessary for the bacteria to be protected in order to increase its lifespan [11]. This protection was achieved by encapsulating the bacteria [12].

Wang et al. [13], have encapsulated bacterial spores in a hydrogel before mixing them with concrete. Crack width of $0.5 \mathrm{~mm}$ was completely filled by the calcium carbonate precipitation. The water absorption was also decreased to $68 \%$. In other investigations, immobilization of bacteria in microcapsule led to a more enhanced performance in which the maximum crack width 970 um was filled. More recently, bacteria was encapsulated in graphite nanoplates [14]. The result has shown that crack width of $0.81 \mathrm{~mm}$ was sealed for specimens pre-cracked at 3 and 7 days. Achal [15] and Mostavi [16] also evaluated self-healing efficiency based on the depth of crack plugged. They stated that the cracks were plugged up to crack depths of $27.2 \mathrm{~mm}$ and $32 \mathrm{~mm}$, respectively. Achal [15] was demonstrated the bio-cementation ability of a bacterial strain Bacillus sp. CT-5 to seal cracks. On the other hand, Mostavi [16] used double-walled sodium silicate microcapsules.

All the self-healing approaches for cracked concrete revealed that the encapsulation technique was more effective due to extension of the lifespan of bacteria for prolonged performance. And also larger size cracks were completely filled using the bio-based materials.

Recently, liquid-based repair materials in the field of self-healing through the use of microbial induced

\footnotetext{
* Corresponding author: prima.yane.putri@gmail.com
} 
precipitation (MIP) have been conducted [17]-[25]. The bio-based repair system as presented in this paper is a liquid-based system which transports the bio-based agent into concrete. The bio-based repair material is comprised of yeast, glucose as organic nutrient source and calcium acetate as calcium source which were selected as basic constituents. Microbial metabolism produces carbon dioxide provides carbonate ions which are leading to calcium carbonate precipitations formed with calcium source mixed in bio-based repair materials. It presents that bio-based repair materials using yeast microbial metabolism could precipitate calcium carbonate crystals [21]. Consequently, it is important to gather more results in simulating real conditions before applying to a practical scale.

Putri, et al. [22]-[24] observed precipitation of calcium carbonate caused by metabolic activity of stagnant bio-based material in the test tubes. The precipitates are mainly comprised of calcium carbonate up to $48 \mathrm{~h}$ after mixed. It reached about $0.388 \mathrm{~g}$ in the $30 \mathrm{ml}$ test tube. This research investigated precipitation of bio-based material that flows in cracked concrete. Also, this study investigated the applicability of the biobased materials to repair leakage in concrete-slab. Since the amount of precipitation of bio-based material is a few, it was necessary to apply the mixture to the concrete specimens with leakage and repeat for several times until the cracks were completely sealed.

In this research, water permeability test and observation with a microscope were carried out to evaluate the effectiveness of the bio-based materials for sealing cracks. In addition, the tests were conducted at microscale to identify and characterize the precipitated materials within concrete cracks after sealing. The precipitates were also tested for Fourier-Transformed Infra-Red spectroscopy (FT-IR) and X-Ray Diffraction (XRD) analysis for mineral identification formed through the microbial metabolic process of bio-based materials in mixtures.

\section{Material and Methods}

\subsection{Scope of investigation}

The investigation deal with the preparation of selected mixtures, preparation of the leakage specimens, the experimental method and the results of the permeability measurement. The specimens were produced with crack widths of $0.6 \mathrm{~mm}$. All test were performed on five specimens.

Table 1 Mix proportion of concrete specimen

\begin{tabular}{ccccc}
\hline w/c (\%) & Slump & \multicolumn{2}{c}{ Air volume (\%) } & Admixture \\
\hline 55 & 8.5 & \multicolumn{2}{c}{4.5} \\
\hline \multicolumn{5}{c}{ Amount $\left(\mathrm{kg} / \mathrm{m}^{3}\right)$} \\
\hline Water & Cement & Sand & G1 & G2 \\
\hline 175 & 318 & 864 & 383 & 572 \\
\hline
\end{tabular}

The mix proportion of the concrete is shown in Table 1. Fine aggregate, has a dry density of $2.65 \mathrm{~g} / \mathrm{cm} 2$ and water absorption rate $1.68 \%$. For coarse aggregate G1 and coarse aggregate G2 were crushed stone No. 5 (sizes are from 25.0 to $12.5 \mathrm{~mm}$ ) and No. 6 (sizes are from 19.0 to $9.5 \mathrm{~mm}$ ) respectively, with density $2.70 \mathrm{~g} / \mathrm{cm} 2$ and water absorption rate of $0.66 \%$. Maximum size of the coarse aggregate is $20 \mathrm{~mm}$. All material was produced by Kagi-o, Shirokawa-cho, Seiyo City, Ehime prefecture. This specimen using Ordinary Portland Cement (OPC), and put in room temperature controlled at $20^{\circ} \mathrm{C}$. All the concrete specimens were cured in a sealed condition until 24 hours after placing. After one day, the form was removed. After that, the concrete specimens were cured in wet condition. After 28 days, leakage was set by arranging the concrete specimens.

The concrete specimen is propped horizontally. The dimension of the specimen is $400 \times 150 \times 50 \mathrm{~mm}$ (bottom

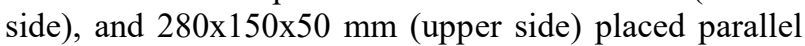
and made leakage subsequently with the crack widths of specimens were set to $0.6 \mathrm{~mm}$. These specimens were sealed with waterproof tape to prevent repair mixtures from leaking through the right and left side of specimens as shown in Fig. 1.

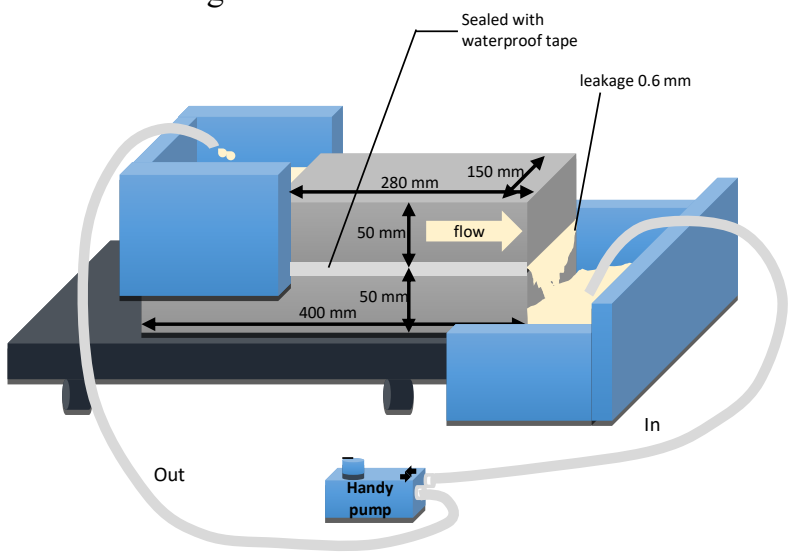

Fig. 1 Experimental set-up for bio-based repair materials and water permeability test

\subsection{Application of bio-based repair materials}

Based on the result of previous experiments carried out by Putri et al. [24], the highest calcium carbonate precipitates were found to the concentration of tris buffer solution in the range of 0.5 to $0.75(\mathrm{~mol} / \mathrm{L})$ for initial $\mathrm{pH}$ adjusted to 9.0. The concentration of dry yeast were specified as $27 \mathrm{~g} / \mathrm{L}$, which were mixed with glucose and calcium acetate with concentrations of $0.3 \mathrm{~mol} / \mathrm{L}$ and $0.15 \mathrm{~mol} / \mathrm{L}$ respectively. The basic constituents of selected mixture for bio-based materials as shown in Table 2.

Table 2 Basic constituents of bio-based materials

\begin{tabular}{cccc}
\hline $\begin{array}{c}\text { Tris } \\
(\mathrm{mol} / \mathrm{L})\end{array}$ & $\begin{array}{c}\text { Dry yeast } \\
(\mathrm{g} / \mathrm{L})\end{array}$ & $\begin{array}{c}\text { Glucose } \\
(\mathrm{mol} / \mathrm{L})\end{array}$ & $\begin{array}{c}\text { Calcium acetate } \\
(\mathrm{mol} / \mathrm{L})\end{array}$ \\
\hline 0.75 & 27 & 0.3 & 0.15 \\
\hline
\end{tabular}




\subsection{Water Permeability Test}

In this work, the leakage (permeability) test has designed rather simple and can be described as follows. If water flows through the leakage in concrete, it will end up flowing out from the other end. Water will leak out from the gaps of concrete. The effectiveness of biobased repair materials was evaluated based on consecutive measurements once per 24 hours for the reduction of water leakage in the concrete specimens.

Five specimens were set to different slope and will show various initial flow rate. The initial flow rate is shown in Table 3.

Table 3 Five specimens with various flow rate

\begin{tabular}{ccc}
\hline $\begin{array}{c}\text { Specimen } \\
\text { number }\end{array}$ & Crack width $(\mathrm{mm})$ & $\begin{array}{c}\text { Initial flow rate } \\
\left(\mathrm{cm}^{3} / \mathrm{s}\right)\end{array}$ \\
\hline 1 & 0.6 & 1.1 \\
2 & 0.6 & 3.4 \\
3 & 0.6 & 5.8 \\
4 & 0.6 & 6.7 \\
5 & 0.6 & 8.9 \\
\hline
\end{tabular}

Before the selected mixtures were poured into the crack, water permeability tests were carried out as benchmarks. The quantity of water flowing through the crack under gravity pressure were measured for 5 minutes. And then, selected mixtures were poured into the crack. A container is placed underneath the specimen to collect the water drained out through the leakage. The digital scale with a maximum capacity of $2000 \mathrm{~g}$ and resolution $0.1 \mathrm{gr}$ is used to measure the weight over time of the water outflow from the leakage. It was removed prior to the water permeability tests which were finally carried out using the specimens in which cracks were supposed to be sealed with precipitated calcium carbonate. In case there is no leakage in the main body or the cracks is sealed already, the water will be no flow at all. A manual stopwatch was used to monitor this time interval.

The application of the selected mixture to cracked concrete specimens was carried out from the back side of concrete specimen via ponding. First, $540 \mathrm{~mL}$ of the mixture was poured into the specimen in each application. Using the hand pump, the mixture was cycling in and out through the leakage and it was carried out once per two days.

It is noted that the right and left side of specimen sealed. Thus, the less viscous mixture essentially flowed out through the cracked specimen unless bonding between cracked surface and precipitates was formed immediately after they flowed. 24 hours after leak was stopped, surface of the leakage in concrete specimens was observed using a portable digital microscope. Result of observation as shown in Fig. 2.

\subsection{Evaluation techniques of calcite precipitation by FT-IR and XRD}

The calcium carbonate precipitation deposited in the specimens is formed with the aid of a pincer by gentle scrapping the surface of the concrete was analyzed using Fourier-Transformed Infra-Red spectroscopy (FT-IR). Infrared spectroscopy is a technique based on the vibrations of the atoms of a molecule. It is used for the determination of molecular structure or the identification of chemical species. A vibration will be infrared active if a change in the dipole moment of the molecule occurs during the vibration. An infrared spectrum consists of a series of bands or peaks which result from the absorption by a part of the molecule of the incident radiation at particular energy [26]. FT-IR spectroscopy is especially favored due to its versatility and non-destructiveness. It is a fast and cost-effective technique, as it does not require a sample preparation step [27]. This analysis requires a tiny amount of sample $(<5 \mathrm{mg})$, and furthermore, no preparation or dilution of the sample is needed [28].

XRD Analysis was carried out using the precipitation left on the specimen. Each sample was crushed and pulverized to an average particle size less than 10 microns, and then mounted onto an instrument-specific plastic slide plates. Then the mass absorption coefficient of the sample was determined by X-ray transmission. The XRD pattern was obtained by scanning from 5 to 50 degrees, 2 theta using a vertical X-ray diffractometer. The components of the sample were identified by comparing them with database powder diffraction PDF4/Mineral 2015 established by the International Centre for Diffraction Data [29].

\section{Results and discussion}

\subsection{Observation by the microscope}

For all specimens, the complete repairing was confirmed by the observation with the microscope after stopping leakage. The repairing effect due to the precipitation up to around nine days.

The comparison picture in Fig. 2 tells us that the biobased materials affect close the leakage in the concrete specimens. It shows the bio-based materials leads to remarkable repairing. The newly formed materials suspected as Ca-based minerals.

Fig. 2 displays the surface of leakage in concrete specimens (flow-out area) before and after the water permeability test is carried out. Formation of suspected newly Ca-based materials is visually seen. Mostly, the calcium carbonate precipitated in the crack of the specimen. The widespread precipitates in the specimens lead to the significant decrease in the water permeability. Furthermore, the results suggested that precipitated calcium carbonate in cracked part concomitant with seeping into deeper zones of concrete specimens was crucial to decrease water leakage effectively.

\subsection{Water flow through leakages}

A water permeability test was carried out before and after the mixture was poured into the cracked specimen to evaluate the effectiveness of the liquid-based repair mixture for leakage in concrete. Table 4 shown 
measuring water permeability time for concrete specimen. The rate of water flowing through the cracks in the concrete specimens was measured at predetermined intervals up to $300 \mathrm{~s}$ as shown in Fig. 3. As can be seen, the water flowing through the cracked section was substantially decreased, which was prominent in the case of mixture poured into the specimens after the mixture was left in room conditions.
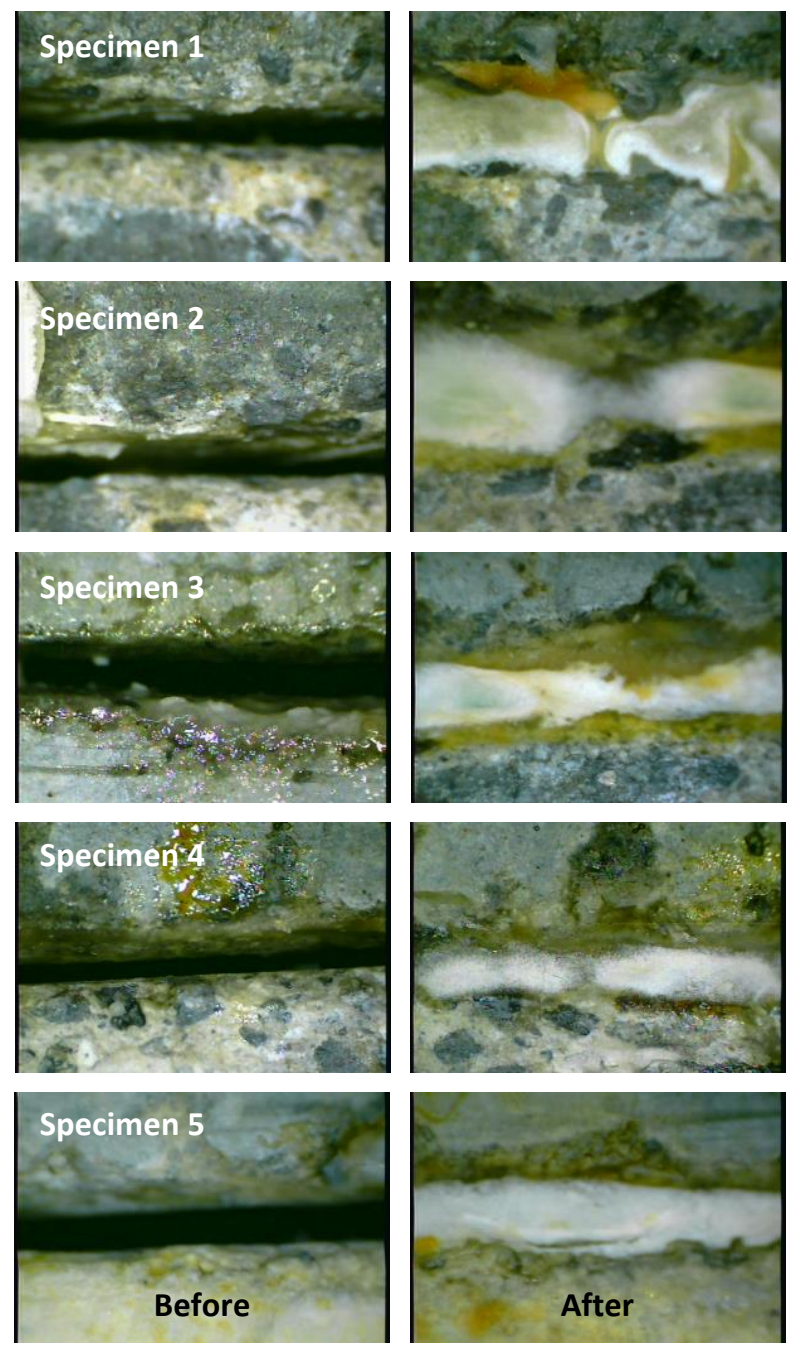

Fig. 2 Leakage of concrete specimen before and after pouring bio-based repair materials (60x magnification). The newly formed materials suspected as Ca-based minerals.

Table 4 Measuring water permeability time

\begin{tabular}{cc}
\hline Case & Application time \\
\hline 0 & Before repaired \\
1 & After 24 hours \\
2 & After 48 hours \\
3 & After 72 hours \\
4 & After 96 hours \\
5 & After 120 hours \\
7 & After 144 hours \\
8 & After 168 hours \\
9 & After 192 hours \\
10 & After 216 hours \\
\hline
\end{tabular}

Water flow per minute varied widely until 30 minutes passed and became almost constant after that. Specimens No.1-5, whose cracks were confirmed to be completely closed by the microscope, showed almost zero water flow after $216 \mathrm{~h}$. When the microscope confirmed complete repairing of specimens, those specimens had high water tightness under gravity pressure.

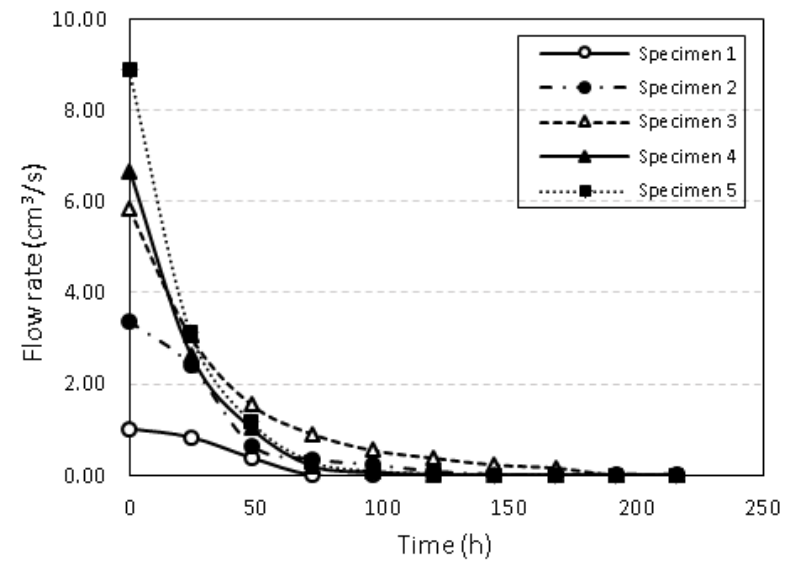

Fig. 3 Flow rate for each specimen up to $216 \mathrm{~h}$ pouring biobased repair materials.

Fig 3 shows flow rate of the specimens until the cracks sealing. Flow rate is the slope of the straight line between amount of flow $\left(\mathrm{cm}^{3}\right)$ and time (s). Furthermore, post-repairing permeability test revealed a zero slope which can be interpreted there was no water flow out from the crack.

From Fig. 3 it can be seen that in case of ambient temperature $\left(\mathrm{T}=20^{\circ} \mathrm{C}\right)$, a specimen with initial flow rate $1.1 \mathrm{~cm}^{3} / \mathrm{s}$ shows the fastest repairing. After only $48 \mathrm{~h}$ the flow rate amounts to about less than $0.5 \mathrm{~cm}^{3} / \mathrm{s}$. In case of a crack with initial flow rate $3.4 \mathrm{~cm}^{3} / \mathrm{s}$, after $48 \mathrm{~h}$ the flow rate reach to $2.419 \mathrm{~cm}^{3} / \mathrm{s}$. For specimen 3,4 and 5 , after $48 \mathrm{~h}$ flow rate amount approximately above $1 \mathrm{~cm}^{3} / \mathrm{s}$. After $72 \mathrm{~h}$, the flow rate amount for all specimen reach about below $1 \mathrm{~cm}^{3} / \mathrm{s}$, even the initial flow rate each specimen were different. It reaches amount below $0.04 \%$ of the initial flow rate for each specimen after $120 \mathrm{~h}$. It was confirmed the previous research that the bio-based materials can recognize at a crack width of $0.6 \mathrm{~mm}$ after 216h ( 9 days).

Based on Fig 3, show the faster healing of cracks that have the smaller initial flow rate whereas the curves have shifted to a lower level. Also, it is clearly visible that in case of an equal crack width of $0.6 \mathrm{~mm}$, for different initial flow rate until $8.9 \mathrm{~cm}^{3} / \mathrm{s}$ those specimens show the similar healing behavior. After $216 \mathrm{~h}$, the flow rate was at approximately $0 \%$ of its initial flow rate. Moreover, it was confirmed the initial flow rate for the same crack width does not influence the time for crack sealing.

Based on previous research[24], amount of precipitates is mainly comprising calcium carbonate up to $48 \mathrm{~h}$ after they were mixed which seemed to reach about $0.388 \mathrm{~g}$ in the $30 \mathrm{ml}$ test tube. The volume of the gap is $68.292 \mathrm{~cm}^{3}$ and based on the calculation, required $5280.3 \mathrm{~mL}$ of bio-based materials to fill the leakage for $0.6 \mathrm{~mm}$ crack width. Furthermore, it will be possible to 
fill the cracks by flowing ten times of $540 \mathrm{~mL}$ of biobased materials. In fact, not all the gaps were filled with calcium carbonate, but because the cracks were partially filled with calcium carbonate, flow rate of water leakage became zero. Fig.4 shows the surface of concrete specimens after the water permeability test were conducted. It indicates that mostly precipitation has occurred at inflow area.

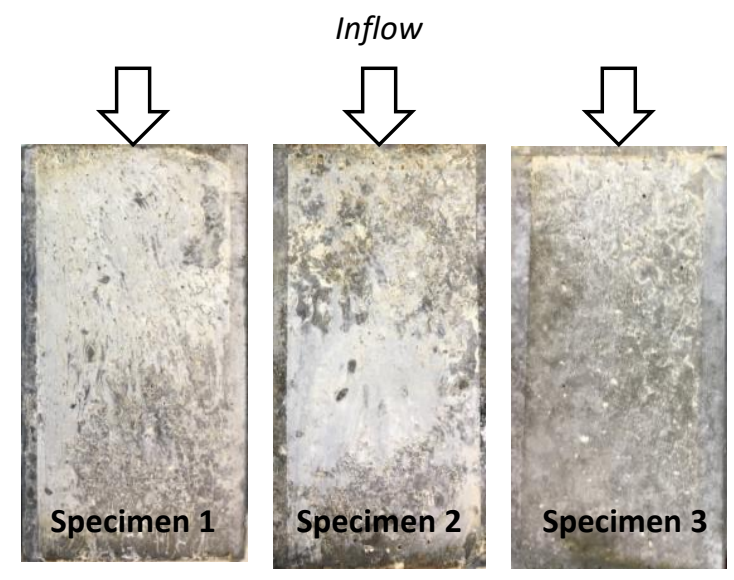

Fig. 4 Surface of specimens 1-3 after pouring bio-based repair materials.

Comparing with the previous research[30], for the crack width $0.2 \mathrm{~mm}$, can seal the cracks in 4 days. It has been shown the decrease of the flow rate depends on crack width. Smaller cracks do seal faster than greater ones. In regards to repairing of cracks, the conclusion can be drawn that under gravity pressure. The results indicate that cracks opening accelerate water flow rate in concrete.

\subsection{FT-IR and XRD Analysis}

Fig. 5 and 6 present the images of FT-IR and X-Ray Diffraction (XRD) observation. The images were taken from the precipitation on the surface of each specimen. Observation revealed Ca-based surface layer which may be attributed due to carbonation.

The FT-IR analysis confirms the chemical element of calcium carbonate in the crystal which is essentially associated with calcium carbonate precipitated mediated by bio-based repair materials. The IR Spectra were recorded using Thermo Scientific Nicolet iS5 Spectrometer and stores using spectroscopic software (Omnic software)[28]. Fig. 5 is the spectra of FT-IR analysis on precipitate scrapped from the specimen after crack sealing. For specimen 1, the peaks at 1403.924, 1029.801 and 87.596 indicated the presence of calcium carbonate. For precipitation at specimen 2 and 4, the signals at $1401.995,1029.801$ and 871.667 show the presence of calcium carbonate respectively. Correspondingly, a similar tendency was observed as shown in spectra at precipitation of specimen 3. It shows peaks 1405.852, 1025.944 and 871.667. Moreover, precipitation at specimen five also indicates the presence of $\mathrm{CaCO}_{3}$, the peaks at $1398.138,1037.515$ and 871.667. These spectra were compared to the standard spectrum of calcium carbonate from NIST Standard Reference
Database[31]. As a result, this spectrum shows that the precipitate is composed in majority of calcium carbonate. This result leads to the implication that biobased materials can successfully as crack repairing materials.

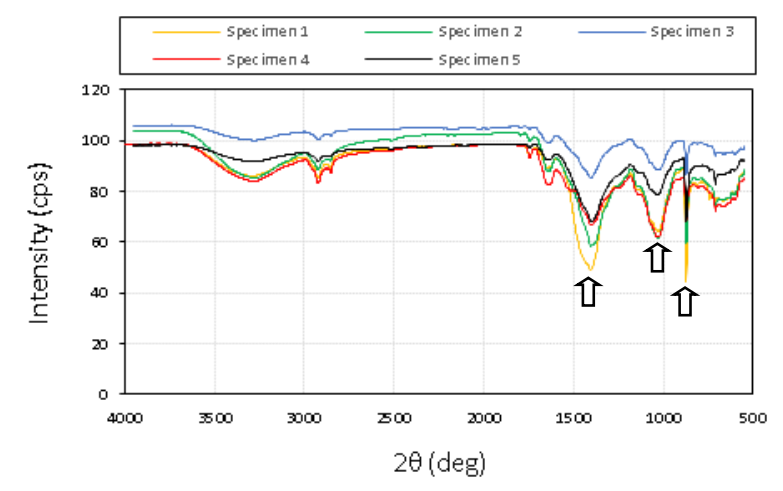

Fig. 5 Spectra of FTIR Analysis for five specimens

On the other hand, the similar precipitation assessed by XRD Analysis to confirm the polymorph as crystals. For the precipitation in specimen of $0.6 \mathrm{~mm}$ crack width, the XRD patterns of the precipitates obtained in the presence of $\mathrm{CaCO}_{3}$ are presented in Figure 6.

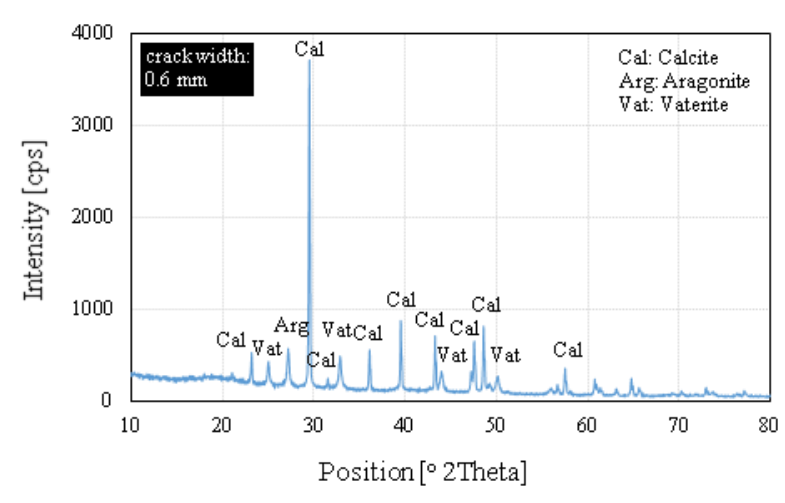

Fig. 6 XRD pattern for specimens with $0.6 \mathrm{~mm}$ crack width

In the precipitation after $216 \mathrm{~h}$, the three polymorph of $\mathrm{CaCO}_{3}$ (calcite, aragonite and vaterite) coexisted. Calcite was dominant polymorphs. There were nine peaks of calcite and four peaks of vaterite respectively. Only one peak of aragonite polymorph in the calcium carbonate precipitation. It was indicating that precipitation of calcium carbonate has stable, because calcite is the stable style of crystal polymorph under ambient condition. Correspondingly, XRD analysis confirmed the calcite is the dominant polymorph of $\mathrm{CaCO} 3$ materials on the precipitation formed of biobased material for repairing concrete in ambient temperature.

\section{Conclusions}

The results obtained via water permeability tests carried out using leakage specimens, for the case of specimens with crack width of $0.6 \mathrm{~mm}$, the liquid-based repair materials could decrease water leakage to zero after 216 hours by continously pouring bio-based repair materials. 
Also, this study confirmed the initial flow rate for the specimens with the crack width does not influence time for crack sealing.

It shows the effectiveness of bio-based repair materials in decreasing water leakage of concrete. FT-IR and XRD analysis also confirmed the element of calcium carbonate in the crystal which is essentially associated with calcium carbonate precipitated mediated by biobased repair materials. As a future investigation, a filling method will be examined in which precipitation by biobased repair material fill the whole area inside the gap.

This research was supported by Grant-in-Aid for Scientific Research (B): 15H04025. Authors greatly appreciate for the financial support. The first author also acknowledges to the Government of Republic of Indonesia through the Directorate General of Human Resource for Science, Technology and Higher education for the scholarship.

\section{References}

1. Japan Society of Civil Engineers, Standard specifications for concrete structures-2007: Design, 15. Japan Society of Civil Engineers, (2007)

2. British Standart Institution, BS 8110-1:1997. Structural use of concrete. Part 1: Code of practice for design and construction, December. British Standart Institution, (1997)

3. N. Z. Muhammad et al., "Tests and methods of evaluating the self-healing efficiency of concrete: A review," Constr. Build. Mater., 112, 1123-1132, (2016)

4. A. Keyvanfar, "Application of Proteus mirabilis and Proteus vulgaris mixture to design selfhealing concrete Application of Proteus mirabilis and Proteus vulgaris mixture to design selfhealing concrete," May, (2015)

5. E. Tziviloglou, V. Wiktor, H. M. Jonkers, and E. Schlangen, "Bacteria-based self-healing concrete to increase liquid tightness of cracks," Constr. Build. Mater., 122, 118-125, (2016)

6. E. Schlangen, H. Jonkers, S. Qian, and a Garcia, "E. Schlangen, H. Jonkers, S. Qian \& A. Garcia," Proc. Fract. Mech. Concr. Concr. Struct., 7, 291-298, (2010)

7. H. M. Jonkers, A. Thijssen, G. Muyzer, O. Copuroglu, and E. Schlangen, "Application of bacteria as self-healing agent for the development of sustainable concrete," Ecol. Eng., 36, 230-235, (2010)

8. J. Wang, K. Van Tittelboom, N. De Belie, and W. Verstraete, "Use of silica gel or polyurethane immobilized bacteria for self-healing concrete," Constr. Build. Mater., 26, 532-540, (2012)

9. S. S. Bang, J. K. Galinat, and V. Ramakrishnan, "Calcite precipitation induced by polyurethaneimmobilized Bacillus pasteurii," Enzyme Microb. Technol., 28, 404-409, (2001)
10. J. M. Irwan and N. Othman, "An Overview of Bioconcrete for Structural Repair," Appl. Mech. Mater., 389, 36-39, (2013)

11. K. Van Tittelboom, N. De Belie, W. De Muynck, and W. Verstraete, "Use of bacteria to repair cracks in concrete," Cem. Concr. Res., 40, 157-166, (2010)

12. J. Y. Wang, D. Snoeck, S. Van Vlierberghe, W. Verstraete, and N. De Belie, "Application of hydrogel encapsulated carbonate precipitating bacteria for approaching a realistic self-healing in concrete," Constr. Build. Mater., 68, 110119, (2014)

13. J. Y. Wang, D. Snoeck, S. Van Vlierberghe, W. Verstraete, and N. De Belie, "Application of hydrogel encapsulated carbonate precipitating bacteria for approaching a realistic self-healing in concrete," Constr. Build. Mater., 68, March 2016, 110-119, (2014)

14. W. Khaliq and M. B. Ehsan, "Crack healing in concrete using various bio influenced selfhealing techniques," Constr. Build. Mater., 102, 349-357, (2016)

15. V. Achal, A. Mukerjee, and M. Sudhakara Reddy, "Biogenic treatment improves the durability and remediates the cracks of concrete structures," Constr. Build. Mater., 48, 1-5, (2013)

16. E. Mostavi, S. Asadi, M. M. Hassan, and M. Alansari, "Evaluation of Self-Healing Mechanisms in Concrete with Double-Walled Sodium Silicate Microcapsules," J. Mater. Civ. Eng., 27, p. 4015035, (2015)

17. S. Kawasaki, A. Murao, N. Hiroyoshi, M. Tsunekawa, and K. Kaneko, "Fundamental Study on Novel Grout Cementing Due to Microbial Metabolism," J. Japan Soc. Eng. Geol. Geol., 47, 2-12, (2006)

18. V. Wiktor and H. M. Jonkers, “Assessment of the functionality of bacteria-based repair system for concrete through ESEM analysis," in EMABM 2015: Proceedings of the 15th Euroseminar on Microscopy Applied to Building Materials, Delft, The Netherlands, 17-19 June 2015, 3, 165-169 (2015)

19. F. Kubo, S. Okazaki, and I. Ujike, "Development of Microbial Metabolic Processes to Repair Concrete Joint Leakage," Adv. Mater. Res., 845, 158-162, (2014)

20. I. Ujike, F. Kubo, K. Kawaai, and S. Okazaki, "Influencing Factors Affecting Microbial Metabolic Processes of Bio Materials Used for Leakage Parts in Concrete," in 5th International Conference on Concrete Repair, 3, 127-133, (2014) 
21. K. Kawaai, I. Ujike, S. Yamamoto, and P. Y. Putri, Some considerations on precipitation rate of calcium carbonate in bio-based materials used for concrete repair. Aristotle University Thessaloniki: CRC Press,( 2016)

22. P. Y. Putri, K. Kawaai, I. Ujike, and S. Yamamoto, "Effect of Temperature on Precipitation Rate of Calcium Carbonate Produced through Microbial Metabolic Process of Bio Materials," Civ. Eng. Dimens., 18, 103108, (2016)

23. P. Y. Putri, I. Ujike, and K. Keiyu, "Influence of the Type of Dry Yeast on Precipitation Rate of Calcium Carbonate in Bio-Based Repair Materials," in EcoGRAFI: Proceeding of 2nd International Conference on Bio-based Building Materials, France, 21-23 June 2017, 133-139 (2017)

24. P. Y. Putri, K. Kawaai, I. Ujike, and H. Okuno, "Influence of Different Concentration of Tris Buffer Solution on Calcium Carbonate Precipitation in Bio-based Repair Materials," Int. J. Adv. Sci. Eng. Inf. Technol., 7, p. 1879, Oct. (2017)

25. S. Sangadji, "Porous Network Concrete: a bioinspired building component ot make concrete structures self-healing," Delft University of Technology, Delft, (2015)

26. J. Coates, Interpretation of Infrared Spectra, A Practical Approach. Encyclopedia of Analytical Chemistry. Coates Consulting, Newtown, USA: John Wiley \& Sons, Ltd, (2006)

27. L. Chuen Lee, C.-Y. Liong, and A. Aziz Jemain, "Applying Fourier-Transform Infrared Spectroscopy and Self-Organizing Maps for Forensic Classification of White-Copy Papers," Int. J. Adv. Sci. Eng. Inf. Technol., 6, 10331039, (2016)

28. Thermo Fisher Scientific, "Thermo Scientific Nicolet iS5 FT-IR Spectrometer Manual." Thermo Fisher Scientific, USA, (2010)

29. International Center for Diffraction Data, "The Powder Diffraction File (PDF)-4/Minerals." International Center for Diffraction Data, USA, (2015)

30. P. Y. Putri, I. Ujike, and K. Kawaai, "Applicability of Bio-bsed Materials to Repair Water Leakage of Concrete," in Proceedings of the Japan Concrete Institute, 40, (2017)

31. NIST Chemistry WebBook, "NIST Standard Reference Database Number 69," (2016) [Online]. Available from: http://webbook.nist.gov/chemistry/. (Accessed on 2016) 